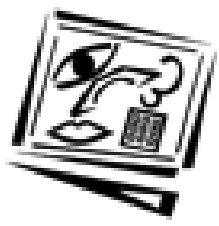

\title{
Challenges of multisite video conferencing: The development of an alternative teaching/learning model
}

\author{
Trish Andrews and Greg Klease \\ Central Queensland University
}

The current trend of globalisation is one that is having a marked impact on society and the area of education in particular is feeling the impact. The dramatic changes that are taking place as a result of globalisation means that the demand for education is increasing significantly. There is growing recognition of not only the need for skills development but also reskilling and a requirement for lifelong learning (Duguet, 1995). Additionally, the increasing availability and stability of communications technologies along with the economic rationalisation that is characteristic of the nineties, means that educational institutions are rethinking the ways in which they deliver teaching and learning activities to an increasingly diverse and dispersed clientele.

\begin{abstract}
This article describes a video conferencing project at Central Queensland University which was implemented to deliver simultaneous interactive instruction in first year chemistry to three campuses - Rockhampton, Mackay, Bundaberg. The article discusses some of the issues of implementing video conferencing as a tool for teaching in a distributed, multi-campus institution and the challenges in developing an interactive teaching and learning model. This includes the need for intensive ongoing staff development and the recognition that staff development for teaching with technology is a long term process of skills acquisition. It also recognises the importance of appropriate student preparation and the part this plays in successfully adopting technologically mediated teaching and learning programs.
\end{abstract}

\section{Introduction}

Central Queensland University (CQU) is an integrated multi-campus regional University located principally in Central Queensland, Australia. The University has five Campuses in Central Queensland with the main campus located at Rockhampton. The other Central Queensland Campuses are Mackay (330 km to the north) Gladstone $(110 \mathrm{~km}$ to the south) Bundaberg ( $350 \mathrm{~km}$ to the south) and Emerald (260 km to the 
west). The University offers on campus courses at each of its sites, across campus courses and distance courses using a variety of delivery techniques. The Bachelor of Applied Science (Chemistry) degree program has been offered to full time on campus students at Rockhampton since the early seventies. In 1989 the first year of the degree course was offered in Mackay and in 1996 the program commenced in Bundaberg. A major problem which confronted staff teaching chemistry (and indeed all other degree science subjects) to the on campus students, was how do we teach the subject matter from a central location and still ensure that the students at the other geographically dispersed locations have the opportunity to develop the same learning experiences and also a sense of belonging to CQU.

\section{Developing multi-campus teaching and learning models}

\section{Initial approach to multi-campus teaching}

The University has been a distance education provider since the early seventies. It has progressively developed as a multi-campus institution over the last twenty years. This experience with distance and distributed teaching was certainly an advantage when the University began developing as a multi-campus institution since it meant that there was a package of learning materials that could be provided to the on-campus students at the other campuses. However, it was quickly identified that school leavers in on-campus learning situations did not have the independent learning skills to study successfully from predominantly print based distance education materials. This prompted the University to seek out a more interactive teaching and learning model involving distributed campus staff as tutors. As a consequence of this Tutored Video Instruction (TVI) was introduced. The TVI technique was initially developed at Stanford University in the USA in the late sixties where it was used as a means of offering postgraduate courses to engineers employed at nearby companies. Evaluation of the use of TVI at CQU (then Capricornia Institute of Advanced Education) showed that the students who received their lectures through TVI sessions performed at least as well as students who attended live lectures at the University (Dekkers et al, 1986).

In TVI, multiple videotape recordings are made of the regular classroom lectures at the delivery campus. These video tapes are then used for instruction with groups of students facilitated by a tutor at the nondelivery campus. During viewing of the video tape the lectures are used as a stimulus to discussion by students and for peer and tutor 
interaction. For it to be successful it has to be used as truly tutored video instruction, that is the tutor needs to be proactive, critical and supportive of the material being discussed. If the lectures became "watching a TV program" the students soon turn off. In many cases of using TVI, true interactivity is not achieved (Crock, Field \& Andrews, 1996).

\section{Introduction of video conferencing}

With the development of the University's video conferencing network, this was seen as a viable method to consistently encourage higher levels of peer, lecturer and tutor interaction. It was therefore decided to trial multi-point video conferencing for the delivery of level 1 chemistry lectures at the beginning of 1996. Point to point video conferencing had been used on previous occasions for contact between staff at other institutions and it was thought that video conferencing could be a suitable vehicle for conducting teaching and learning activities.

Video conferencing is a unique method of providing real time face-toface interaction that enables immediate peer and teacher interaction and feedback. This interaction can minimise feelings of isolation and provide for a richer learning experience for students and staff at geographically separated sites.

Video conferencing technologies are powerful tools for distributed education and play a major role in the creation of new teaching and learning environments that are becoming increasingly common through the use of flexible delivery options. (Bates, 1994)

\section{The video conferencing project}

The video conference trial for level 1 chemistry took place in first semester 1996. A one hour video conference session was conducted for each week of the semester. Tutors at the Bundaberg and Mackay campuses provided on-campus support to students.

The outcomes of the trial indicated the following:

- there are considerable challenges in developing effective interactive multi-campus teaching and learning models

- the role of staff development activities and time for skills acquisition are critical to the success of developing these models 
- on-campus students are generally under prepared for technologically mediated teaching and learning environments and operate more effectively in these environments following preparation programs prior to the commencement of classes.

The use of new technologies in developing alternative teaching and learning environments provides many challenges to both teachers and learners. In this particular project, although the participants set out eager to explore the interactive aspects of the technology, what in fact resulted was a fairly didactic teacher centred model of learning moderated by attempts to involve students in discussion by questions from the lecturer aimed at eliciting responses from the students. In reality staff had limited understanding of how to develop a different model of teaching and learning that included real interactivity. The development of effective teaching and learning environments using media such as video conferencing rely on more student centred approaches to learning. This includes the development of new teaching and learning models that exploit the technology rather than transferring existing teaching and learning models to the new genre.

In many cases students also had little understanding of how to operate in this new environment and of the different expectations of them as learners. Although students were encouraged to interact during the sessions the lecturer experienced little success in encouraging real spontaneous interaction from the students.

As a consequence of this initial experience and the valuable lessons learned from use of this technology on a regular basis it was decided to trial a more structured, student centred tutorial model of teaching and learning based on group work, with the same group of students as in the initial trial. It was felt that this approach would result in a more interactive teaching and learning environment.

\section{Group teaching and learning as an alternative model}

The shift from a didactic model to one of unstructured, spontaneous interaction was asking too much of both teachers and learners and placed unrealistic and unreachable expectations on them. Group work allowed for a structured approach with set roles and expectations for all participants. Groups of three were selected according to a model by Sleet (1996). The roles were manager, questioner/sceptic and recorder/checker. Each role had set tasks and activities and suggested 
strategies for achieving these. Group work of this model also provided learners with the opportunity to view problems and activities from a number of different perspectives. This has a spinoff for graduate work related activities as well and can thus be viewed as educating the learners for real workplace requirements ie cooperative team based tasks/ projects.

As this was a new approach for most participants, video conferencing technology was used for training the learners in the roles of each of the members of the group - manager, questioner/sceptic and recorder/checker.

Each group was given a problem to investigate and was required to present their findings to the class across all campuses. The problems related to key topic areas of the physical chemistry curriculum. For example, students were required to develop solutions using appropriate formulae, calculations and interpretations. The whole class had previously been provided with information on the problems each group would discuss, thus encouraging open interaction during the video conference sessions. Each group had a week to work on solutions to their problem prior to their presentation and discussion. These discussions were facilitated by both the lecturer and tutors at the various sites and proved an effective strategy in involving the wider group of learners.

\section{Evaluation of the group teaching approach}

Evaluation of the group teaching approach was conducted through weekly observations of the video conferenced sessions by the flexible learning adviser involved in the project and also through focus group discussions with participating students at the Mackay, Bundaberg and Rockhampton campuses.

From these observations it became clear that this more structured approach to interaction resulted in greater peer and teacher communication. This approach encouraged communication across campuses as well as within campuses. It was also observed that there was a considerable element of peer tutoring within each group involved in the actual preparation of the materials for discussion. The processes of engaging in group work encouraged greater exploration of issues and helped to develop critical thinking skills. As one student remarked

Group work makes us think about and do the problem.

(Klease, Andrews \& Druskovich 1996) 
Using this group work approach students appeared to be more relaxed in presenting their findings to the multi-site group and seemed to be less inhibited by the presence of the camera. This was in marked contrast to the experience in the initial project. Students also appeared to feel comfortable in interrupting and offering their opinions and even in disagreeing with the majority opinion. As well as encouraging more interaction from the students, the lecturer also participated in this more structured, interactive learning environment through providing positive feedback or clarification and explanation as required. This group approach was quite informal and students appeared at ease in making spontaneous remarks and social comments as well as participating in the learning activities. While the initial outcomes of this structured group approach to encourage interaction was successful, it was apparent to the observer that students required further training to make full use of the video conferencing facilities. Students demonstrated little understanding of how to produce materials for the document camera (means of transmitting documents via video conferencing) and some sites also experienced difficulties in operating the controls.

This problem of lack of familiarity with the equipment and limited understanding of how to prepare a presentation using the document camera was also highlighted by the students in the focus group discussions.

Additionally, students commented that this opportunity to interact with peers developed a sense of belonging to the wider University community and of being part of the larger, dispersed group. The students appreciated access to the actual lecturer who had set the assessment activities (assignments and examinations) thus obtaining a first-hand understanding of the level expected. The relatively small numbers of students at each site were also considered a factor in the success of this model for encouraging communication and participation across sites.

Given the dispersed nature of our campuses and the total enrolment numbers at individual sites it is not cost-effective to employ full-time lecturers in each discipline area at each site. Video conferencing overcomes the "access to the expert" gap by providing opportunities for face-to face-interaction on a regular basis. 


\section{The role of staff development and student preparation}

\section{The need for staff development}

Traditionally, in Australian Universities, the majority of teaching staff do not have any kind of formal teaching qualification. This means that most staff develop their understanding of teaching and learning from their own University experience. In the majority of cases this tends to be a fairly traditional lecture/tutorial format.

From the observations of the initial video conference sessions, it soon became clear that there was a need for some staff using technologies such as video conferencing to participate in a "gestation period" (Stacey, 1997) that would enable them to develop a realistic grasp of the ways in which the technology can be used more effectively. A familiarisation process occurring through active use of the technologies is a critical part of the development of new teaching and learning models and requires an investment of time. This "gestation" period enables staff to think about the environments in which they are working and to come to grips with the sometimes subtle differences between "real" and technologically mediated "face-to-face" teaching and learning environments. It enables staff to understand the potential of the technology in terms of what can be realistically accomplished and to have the time and support to "reskill". The results can be very beneficial with possible outcomes including more effective utilisation of the technologies selected and the development of teaching and learning models more suited to the video conference environment.

\section{The need for student preparation}

Learners also are facing challenges in these new environments. Many students still have a traditional view of what a University education means. Thus, they have particular expectations regarding their role and the role of the lecturer. Many students still feel that they need to get their information from the lecturer as the "expert" in order to learn "properly". The notion of taking responsibility for their own learning is quite foreign to many of them.

For the majority of the learners this was a completely new experience and few were comfortable with responding spontaneously in this new environment. For most of us, watching television is a passive activity and we are not expected to respond to it. Many students reported feeling inhibited by being focused on from a number of directions - focus from 
the camera, focus from the class at their site, focus form the class at other sites and focus from the lecturer. In "traditional" class situations it is not uncommon for students to feel inhibited by the presence of their classmates and not wanting to look foolish in front of their peers. For students engaged in video conferencing there is the added pressure of being broadcast to the world, albeit the small world of other campuses. Additionally, some students found the actual presence of the camera very inhibiting and actively sought to stay out of camera range, an experience that is supported by research by Comeaux (1995). Furthermore, many students also expressed a reluctance to break into the lecturer's "precious" time. This is commonly expressed by students in other projects of this type (Andrews \& Klease 1997). Students expressed a preference for interacting with their tutor at their site after the video conference session was completed if there were any points that required clarification. While this is not necessarily a negative, it does limit opportunities for spontaneous interaction during actual video conference sessions.

Many of these difficulties and perceptions regarding alternative teaching and learning environments can be overcome by preparing students for these different environments prior to the commencement of their courses. Regardless of the approach taken, it has become increasingly apparent that students are struggling with the changes in teaching and learning as much as staff and that addressing this issue needs to be seen as a priority.

\section{Conclusions}

This project provided a wealth of opportunities for both professional development for staff and for skills development for students complementary to their knowledge acquisition in chemistry. In the currently evolving education and work markets there is a need for both staff and students to be involved in life long learning processes and to acquire and develop a broad range of skills.

Staff were able to explore the most effective means of using video conferencing technology to achieve positive learning outcomes. The experience of using the technology enabled staff to develop a sound understanding of ways in which the technology could be best utilised which resulted in the moving away from a didactic teacher centred model to a more interactive student centred model. This process of developing understandings about the effective use of video conference 
for teaching and learning in chemistry, through active participation, was a true professional development activity for the staff involved. It is doubtful that such outcomes could be achieved through a workshop activity alone. It is emphasised that the development of an effective model for multi-campus teaching using video conferencing technology is an ongoing professional development process and reflects feedback and evaluation provided by tutors, lecturers and students.

For the students, the introduction of the group teaching model not only resulted in more communication and interaction between peers and lecturer but also encouraged the development of work place competencies valued in the job market. The group work approach encouraged the sharing of knowledge and peer support in a productive, positive environment. This approach also encouraged the development of both critical thinking and problem solving skills as well as encouraging learners towards more independent learning strategies. It is believed that there needs to be a more pronounced shift to a learner centred model of teaching and learning with students developing the skills and confidence to share ideas, challenge opinions and propose solutions in a positive and supportive environment. This approach also highlighted the need for student development for new teaching and learning and environments. It is felt that more extensive student awareness and preparation programs will not only form an essential part of future developments using video conferencing technologies but also provide skills for students to become independent learners.

The development of an interactive group work model for the teaching and learning of Chemistry can be seen as developing an effective teaching and learning environment not only for chemistry but also for other subjects using video conferencing technology. This kind of model may also have applications for nodes of distance education students attending interactive tutorial sessions at open learning centres (remote education support centres) using desktop video conferencing facilities. Video conferencing has become be an essential tool in maintaining course offerings to multi-campus institutions or for dispersed groups of students and has the potential to promote more interactive and effective teaching and learning processes. 


\section{References}

Andrews, T. \& Klease, G. (1997). The role of video conferencing in enhancing teaching and learning via a virtual faculty: Project evaluation CUTSD grant, unpublished report, CQU.

Bates, T. (1994). The educational aspects of the telecommunications revolution. In Proceedings ICDE-DEANZ, Windows of the Future Conference, Wellington, New Zealand.

Comeaux, P. (1995). The impact of an interactive distance learning network on classroom communication. Communication Education, Vol.44.

Crock, M., Field, P. \& Andrews, T. (1996). A report on the investigation into student and tutor perceptions on the use and adequacy of tutored video instruction (TVI). Central Queensland University, Rockhampton.

Dekkers, J., et al (1986). The use and evaluation of tutored video instruction at the Capricornia Institute, Gladstone Centre, CIAE.

Duguet, P. (1995). Education: Face to Face or Distance? The OECD OBSERVER, No. 194, June/July.

Klease , G, Andrews, T \& Druskovich, D. (1996). Blurring the boundaries developing effective teaching/learning models for multi-site video conferencing. In Proceedings, Second International Open Learning Conference, Open Learning '96, Brisbane.

Sleet, R., et al (1996). Broader Skill Requirements of Science Graduates. University of Technology, Sydney.

Stacey, E. (1997). The trials, tribulations and triumphs of teaching with technology: coping with computer mediated communication in distance education. Paper presented at the ODLAA Conference Open, Flexible and Distance Learning: Education and Training in the 21st Century, Launceston. 